\section{De la TRANSLATion À LA TRADUCTION (1988)}

\author{
ANTOINE BERMAN
}

\section{Avant-propos}

Le texte qu'on va lire est un extrait d'un ouvrage, Jacques Amyot, traducteur français, qui devrait parâ̂tre prochainement en co-édition franco-québécoise. Son thème fondamental est l'apparition du terme de traduction au XVIe siècle, qui vient remplacer, dans les pays de langue romane, celui de translation, que le monde anglo-saxon a gardé jusqu'à maintenant. En arrière-fond, le lecteur pourra percevoir, à travers une analyse paraissant purement «sémantique», ce qu'il en est de la place de la «traduction» dans une culture, selon qu'on la nomme, justement, traduction (comme en français, en espagnol, en italien et en portugais) ou translation, comme en anglais. Traduction ou translation? Telle est, aujourd'hui, peut-être, la question. En même temps, ce texte s'efforce d'ouvrir à la nécessité d'une réflexion historico-lexicale sur la traduction ou, plus précisément, d'une archéologie de la traduction dans l'espace de la culture occidentale.

\section{DA TRANSLAÇÃO \\ À TRADUÇÃO ${ }^{1}$}

\author{
ANTOINE BERMAN
}

\section{Prólogo}

Este texto é um excerto da obra Jacques Amyot, traducteur français, que deverá ser lançada proximamente em uma co-edição franco-canadense. Seu tema fundamental é o aparecimento do termo tradução no século XVI, vindo a substituir, nos países de língua românica, translação, vocábulo que o mundo anglo-saxão mantém até hoje. Como pano de fundo, o leitor poderá perceber, através de uma análise aparentemente de pura "semântica", aquilo que está no lugar da "tradução" em uma cultura, de acordo com a forma como a nomeamos: justamente, tradução (como em francês, em espanhol, em português e em italiano) ou translação, como no inglês. Tradução ou translação? Talvez, hoje, essa seja a questão. Ao mesmo tempo, este texto esforça-se em trazer à discussão a necessidade de uma reflexão histórico-lexical sobre a tradução ou, mais precisamente, de uma arqueologia da tradução no espaço da cultura ocidental.

1 Publicado originalmente na revista TTR - Traduction, Terminologie, Rédaction. Études sur le texte et ses transformations. Volume 1, numéro 1, 1er semestre de 1988. Université du Québec. 
$* * *$

La Renaissance se signale d'abord par un accroissement massif $\mathrm{du}$ volume des traductions, accroissement qui n'est comparable qu'à celui qui a eu lieu dans la seconde moitié du XXe siècle. En surface, ce phénomène est lié à divers facteurs comme l'essor de l'imprimerie, la redécouverte de l'Antiquité et l'intérêt accru pour les littératures étrangères contemporaines, notamment celles d'Italie et d'Espagne. La Réforme est également à l'origine de nombreuses traductions et retraductions.

Plus profondément, cet accroissement correspond à ce que Ton pourrait appeler une illimitation du champ de traduction. Au moyen âge, ce champ était clos: ce qu'il y avait à traduire, c'était essentiellement le corpus des auctoritates, des grands textes consacrés par l'Église et la «clergie». A la Renaissance, le champ du traduisible devient illimité: n'importe quel texte, de n'importe quel genre, de n'importe quelle langue, est désormais considéré comme bon à traduire. En conséquence, non seulement on se met à traduire de tout, mais on cultive confusément l'ambition de «tout» traduire. Pareille ambition ne se retrouve que dans l'Allemagne romantique et classique. Cette illimitation du champ de la traduction fait que le nombre des textes traduits augmente vertigineusement.

À son tour, la masse de ces textes crée un public pour lequel lire, en général, signifie avant tout lire des traductions. Pour lequel un «livre», c'est avant tout une œuvre traduite. Pendant presque tout le XVIe siècle,
O Renascimento é marcado primeiramente por um aumento massivo do volume de traduções, crescimento esse só comparável com o que teve lugar na segunda metade do século XX. Na superfície, esse fenômeno está ligado a diversos fatores, como a descoberta da imprensa, a redescoberta da Antigüidade e o advento do interesse pelas literaturas estrangeiras contemporâneas, em especial as da Espanha e da Itália. A Reforma também está na origem de numerosas traduções e retraduções.

De uma forma mais profunda, esse crescimento corresponde ao que poderíamos chamar de uma ilimitação do campo da tradução. Na Idade Média, esse campo estava fechado: o que havia para ser traduzido era essencialmente o corpus das autoridades, os grandes textos consagrados pela igreja e pelo "clero". No Renascimento, o campo do traduzível torna-se ilimitado: não importa que texto, não importa de que gênero, não importa de que língua, tudo, desse momento em diante, é considerado como digno de ser traduzido. Como conseqüência, não apenas se começa a traduzir de tudo, mas se cultiva confusamente a ambição de "tudo" traduzir. Tal ambição só é encontrada na Alemanha romântica e clássica. Esse iluminismo do campo da tradução fez com que o número de textos traduzidos aumentasse de forma vertiginosa.

Essa massa desses textos, por sua vez, criou um público para o qual ler, em geral, significa antes de tudo ler traduções; para quem um "livro" é antes de tudo uma obra traduzida. Durante quase todo o século XVI, $o$ 
le traduit fait autorité. D'où, entre autres choses, la naissance de ce genre curieux, la pseudo-traduction, dont le chef-d'œuvre est le Don Quichotte de Cervantes, qui se présente ironiquement comme une traduction de l'arabe.

On pourrait dire que, à la Renaissance, ce sont les traductions en tant que telles qui sont devenues les nouvelles auctoritates.

D'où une autre conséquence. Puisque le traduit fait autorité (c'està-dire aussi: se vend souvent bien, peut rapporter charges et honneurs), tout le monde se met à traduire au XVIe siècle. Il n'est guère d'auteur poète comme Marot ou du Bellay, érudit comme Erasme, essayiste comme Montaigne - qui n'ait traduit à cette époque. Activité exercée à un moment ou à un autre par tous ceux qui écrivent, la traduction est simultanément, à la Renaissance, origine et horizon de l'écriture en langue maternelle. En fait, on apprend à écrire en traduisant.

Ce lien de l'écriture avec la traduction, en même temps, se fonde sur une pratique bi ou polylingue de récriture: la maîtrise de la langue à traduire, en effet, s'acquiert en écrivant dans celle-ci. En d'autres termes, l'exercice du thème (au sens large: écrire dans une langue autre que la sienne propre) permet la version, et celle-ci permet à son tour d'écrire en langue maternelle. Telle est la structure triangulaire de l'activité littéraire des hommes de la Renaissance. Mais, des trois modes d'écriture - écrire en langue étrangère, traduire de la langue étrangère, écrire en langue maternelle - , c'est la traduction qui a la préséance, parce qu'elle est pour tous les écrivains de cette époque le lieu traduzido ganha autoridade. De onde temos, entre outras coisas, o nascimento deste gênero curioso, a pseudo-tradução, cuja obra-prima é Dom Quixote, de Cervantes, que se apresenta ironicamente como uma tradução do árabe.

Poderíamos dizer que no Renascimento são as traduções enquanto tais que se tornam as novas autoridades.

Daí advém outra consequência. Porque o traduzido ganha autoridade (quer dizer também que vende bem, pode trazer cargos e honrarias), todo mundo põe-se a traduzir no século XVI. Nessa época, não há quase nenhum autor - poeta como Marot ou du Bellay, eruditos como Erasmo, ensaístas como Montaigne - que não traduza. Atividade exercida em um momento ou outro por todos aqueles que escrevem, a tradução é simultaneamente, no Renascimento, origem e horizonte da escrita em língua materna. De fato, aprendemos a escrever traduzindo.

Essa ligação entre a escrita e a tradução funda-se, ao mesmo tempo, sobre uma prática bi ou polilíngue da escrita: o domínio da língua a ser traduzida, efetivamente, se adquire escrevendo com ela. Em outros termos, o exercício do tema (num sentido amplo: escrever numa língua outra que não a própria) permite a versão e isso permite, por sua vez, escrever na língua materna. Tal é a estrutura triangular da atividade literária dos homens do Renascimento. Mas, dos três modos de escrita - escrever em língua estrangeira, traduzir da língua estrangeira, escrever na língua materna - é a tradução que tem a precedência, porque é, para todos os escritores dessa época, o lugar onde é formada 
où l'on forme sa langue.

Origine de l'écriture, la traduction est aussi son horizon. Pour un homme du XVIe siècle, écrire n'est jamais bien loin de traduire. Non seulement l'écriture vient de la traduction, mais elle ne cesse d'y retourner.

Le constant chassé-croisé de du Bellay entre l'écriture en français, comme les Regrets, l'écriture en latin, comme ses Poemata, et la traduction du latin, comme Virgile, illustre à la fois cette structure triangulaire dont je parlais et le fait que, au XVIe siècle, l'écriture ne peut jamais s'éloigner de la traduction.

Si ce cas est exemplaire, d'autres auteurs illustrent à leur manière ce lien ombilical de l'écriture à la traduction. Rabelais, qui se moque de l'écolier limousin parlant un français latinisé (une sorte de traduction littérale du latin), grécise et latinise luimême sa prose: celle-ci comporte donc de forts éléments traductifs comme les emprunts, les calques, etc.

Calvin n'acquiert la maîtrise du français qu'en traduisant lui-même l'œuvre qu'il a d'abord écrite en latin, L'Institution chrétienne.

Montaigne émaille ses Essais de citations en général non traduites, mais ses textes sont emplis de citations déguisées, d'emprunts intertextuels qui, eux, sont des traductions. Il traduit d'ailleurs l'Apologie de Raymond Sebond, et le Plutarque d'Amyot est omniprésent dans son livre. Comme l'a dit Hélène Nais ${ }^{2}$, si l'on cherchait au XVIe siècle des œuvres entièrement détachées de la traduction, on n'en trouverait que fort peu, a sua língua.

Origem da escrita, a tradução é também o seu horizonte. Para um homem do século XVI, escrever nunca está longe de traduzir. Não apenas a escrita vem da tradução, mas ela não pára de retornar a ela.

O constante vai-e-vem de du Bellay entre a escrita em francês, como em Regrets, a escrita em latim, como em Poemata, e a tradução do latim, como Virgílio, ilustra, por sua vez, essa estrutura triangular da qual falo e o fato de que no século XVI a escrita não podia jamais se afastar da tradução.

Se esse caso é exemplar, outros autores ilustram à sua maneira a ligação umbilical da escrita e da tradução. Rabelais, que ri do estudante de Limousin falando um francês latinizado (um tipo de tradução literal do latim), ele próprio latiniza e greconi$z a$ a sua prosa: essa contém, portanto, fortes elementos tradutórios como os empréstimos, os calcos etc.

Calvino só adquire o domínio do francês ao traduzir a obra que ele havia escrito em latim, $A$ instituição da religião cristã.

Montaigne enfeita os seus Ensaios com citações, em geral, não traduzidas e os seus textos são repletos de citações camufladas, de empréstimos intertextuais que são traduções. Ele traduz, além disso, Apologie, de Raymond Sebond, e o Plutarque, de Amyot, está onipresente em seu livro. Como disse Hélène Nais ${ }^{2}$, se procurarmos no século XVI obras inteiramente desvinculadas da tradução, encontraremos muito poucas e as

\footnotetext{
${ }^{2}$ Hélène Nais, in Ferdinand Brunot, Histoire de la langue française, t. II (Paris, éd. Armand Colin, 1967), p. 486.
} 
et des moins représentatives.

La traduction est donc, à la Renaissance, l'horizon de toute écriture. Elle est la matrice de ce que l'on commence justement à appeler licterature . $^{3}$.

Donc tout le monde traduit, est pris par l'impulsion de traduire, de traduire de tout et n'importe quoi. Mais aussi, n'importe coment. Comme précédemment, on fait des traductions de traductions, on s'attaque à des livres dont on ignore presque la langue et, surtout, on traduit sans aucun principe. Par conséquent, comme le dit du Bellay dans sa Défense et illustration de la langue française, les mauvaises traductions abondent. Et il y a tout un travail, au XVIe siècle, pour remédier à cet état de choses. Estienne critique les traductions de traductions. Dolet, lui, tente de définir les principes que devrait suivre tout traducteur. Le bref texte qu'il a écrit (et qui a connu un vif succès), De la manière de bien écrire d'une langue en l'aultre, doit être lu non pour ce qu'il énonce d'original (Dolet répète ce que disaient déjà les Romains et les Médiévaux), mais pour l'effort de délimitation qu'il constitue.

Cela nous amène à deux autres caractéristiques plus essentielles de la traduction au XVIe siècle. L'époque où l'on traduit massivement de tout, où tout le monde traduit, où le traduit fait autorité, est aussi celle où, pour la première fois en Occident, traduire devient une activité manifeste et définie.

Et cela se voit à deux signes. Le premier, c'est l'apparition d'un terme spécifique pour désigner l'acte menos representativas.

A tradução é, portanto, no Renascimento, o horizonte de toda a escrita. É a matriz daquilo que começamos a chamar justamente de licterature ${ }^{3}$.

Logo, todo mundo traduz, é tomado pelo impulso de traduzir, de traduzir de tudo, não importa o quê. Mas também não importa como. Como antes, fazemos traduções de traduções, nos dedicamos a livros dos quais praticamente ignoramos a língua e, sobretudo, traduzimos sem nenhum princípio. Em conseqüência, como diz du Bellay em Défense et illustration de la langue française, as más traduções tornam-se abundantes. $\mathrm{E}$ há todo um trabalho, no século XVI, para remediar esse estado de coisas. Estienne critica as traduções de traduções. Dolet tenta definir os princípios que todo tradutor deveria seguir. $\mathrm{O}$ breve texto que escreveu (e que teve grande sucesso), De la manière de bien écrire d'une langue en l'aultre deve ser lido não pelo que propõe de original (Dolet repete o que já diziam os romanos e os medievais), mas pelo esforço de delimitação que constitui.

Isso nos leva a duas outras características essenciais do século XVI. A época na qual se traduz massivamente de tudo, na qual todos traduzem, quando o traduzir ganha autoridade, é também quando, pela primeira vez no Ocidente, traduzir torna-se uma atividade manifestada e definida.

$\mathrm{E}$ isso se pode ver em dois sinais. O primeiro é a aparição de um termo especifico para designar o ato

\footnotetext{
${ }^{3}$ Ferdinand Brunot, op. cit., p. 29. Le moyen âge disait lettreüre. [Na Idade Média se dizia lettreüre.]
} 
de traduire. Le second, c'est la multiplication d'écrits sur la traduction.

$$
* * *
$$

Vers 1500 surgit un terme nouveau qui, en principe, ne désigne que l'activité traduisante. Ce terme, pour toutes les langues romanes (et pour l'allemand, qui en donne la transcription littérale), c'est justement traduction.

Le fait que l'acte de traduire commence à être désigné, à l'orée du XVIe siècle, par un terme nouveau et unique est un événement inapparent, mais majeur, de l'histoire de la culture occidentale. Il indique un changement radical dans la manière de percevoir cet acte, et avec lui tous les autres actes d'écriture. Cela ne veut absolument pas dire que ce changement ait été perçu comme tel à l'époque.

$\mathrm{Au}$ moyen âge, l'acte de traduire était désigné par plusieurs termes, parmi lesquels ne figurait justement pas celui de traduction. Le plus courant était celui de translation, que l'anglais a conservé avec le verbe correspondant translater.

Le français médiéval avait espondre, turner, mettre en romanz, enromanchier, et translater 4 .

Cette multiplicité de termes avait plusieurs causes. En premier lieu, l'acte de traduire, qui se définit pour nous par le transfert d'un texte d'une langue à une autre, n'était pas bien clairement distingué d'autres types de rapport aux textes et aux de traduzir. O segundo, a multiplicação de escritos sobre a tradução.

Por volta de 1500 surgiu um novo termo que, em princípio, designa somente a atividade tradutória. Esse termo, em todas as línguas românicas (e em alemão, que faz uma transcrição literal), é justamente traduction [tradução].

$\mathrm{O}$ fato de que o ato de traduzir comece a ser designado, no limiar do século XVI, por um termo novo e único é um acontecimento pouco visível, mas da maior importância na história da cultura ocidental. Indica uma mudança radical na maneira de perceber esse ato e, com ele, todos os demais atos de escrita. Isso não quer dizer, em absoluto, que essa mudança tenha sido percebida como tal na época.

Na Idade Média, o ato de traduzir era designado por muitos termos, entre os quais não figurava justamente o de tradução. O mais comum era translação, que o inglês conservou com o verbo correspondente translater.

O francês medieval tinha espondre, turner, mettre en romanz, enromanchier, e translater [explicar, mudar, passar para o romance, romantizar e transladar $]^{4}$.

Essa multiplicidade de termos tinha muitas causas. Em primeiro lugar, $o$ ato de traduzir, que se define para nós como a transferência de um texto de uma língua a outra, não estava claramente diferenciado de outros tipos de relação entre textos e entre

\footnotetext{
${ }^{4}$ SherrySimon, «Conflits de juridiction», texte inédit, à paraître dans Meta, Montréal. [Texto inédito a ser publicado na revista Meta, Montreal.]
} 
langues. L'écriture médiévale étant essentiellement réordonnancement ou commentaire de textes déjà existants, il était difficile, et dénué de sens, d'isoler l'acte de traduire du reste. C'est là un fait relevé par maints historiens. Ainsi Luce Guillerm écritelle:

Là où le travail d'écriture, celui du juriste ou du médecin, mais aussi celui de l'historien, du philosophe moraliste, sans parler bien sûr du théologien, était discours sur du discours, agencement de textes préalables dédoublés par le commentaire (...) sans que se puisse repérer clairement l'origine des différentes paroles, il n'y avait guère de raisons pour que le traducteur-interprète-commentateur occupe une place distincte ni que la traduction ait à être pensée comme un objet occupant une fonction spécifique dans le champ de la production écrite. ${ }^{5}$ chose:

Bakhtine ne dit guère autre

Au moyen âge (...) les frontières entre «sa» parole et celle d'«autrui» étaient fragiles, équivoques, souvent tortueuses à dessein. ${ }^{6}$

En d'autres termes, la distinction, pour nous évidente, entre un texte original et un texte second (traduction, commentaire, recréation, adaptation) n'existait pas vraiment au moyen âge. Et par conséquent, il ne pouvait y avoir de traduction au sens moderne.

Cette indéfinition était renforcée par le fait que, à l'époque médiévale, il n'y avait pas de frontières linguistiques stables et tranchées. Cette situation (presque inconcevable pour nous) avait au moins deux consé- línguas. A escrita medieval era essencialmente reordenamento ou comentário de textos já existentes, era difícil e sem sentido isolar o ato de traduzir do restante. Esse é um fato relevado por muitos historiadores. Assim escreveu Luce Guillerm:

Naquele tempo, quando o trabalho de escrita, o do jurista ou o do médico, mas também o do historiador, o do filósofo moralista, sem falar sobre o do teólogo, era discurso sobre discurso, disposição de textos previamente desdobrados em comentários (...) sem que se pudesse notar claramente a origem das diferentes falas, não havia razões para que o tradutor-intérprete-comentarista ocupasse um lugar diferenciado, nem que a tradução fosse pensada como um objeto que ocupasse uma função específica no campo da produção escrita. ${ }^{5}$

Bakhtin não pensava diferente:

Na Idade Média (...) as fronteiras entre o "seu" discurso e o do "outro" eram frágeis, equívocas, muitas vezes tortuosas. ${ }^{6}$

Em outros termos, a distinção, que para nós é evidente, entre um texto original e um texto secundário (tradução, comentário, recriação, adaptação) não existia verdadeiramente na Idade Média. E, como consequência, não podia haver tradução no sentido moderno.

Essa indefinição era reforçada pelo fato de que, na época medieval, não havia fronteiras linguísticas estáveis e demarcadas. Essa situação (quase inconcebível para nós) tinha no mínimo duas consequências. Em

${ }^{5}$ Luce Guillerm, «la Topique de la traduction au XVIe siècle en France», Revue des sciences humaines, Lille III, 1980-1984, n 180 , p. 13.

${ }^{6}$ M. Bakhtine, Esthétique et théorie du roman (Paris, Gallimard, 1975), p. 426. 
quences. En premier lieu, certains types de textes devaient être écrits dans des langues déterminées, quelles que fussent la nationalité et la langue de leurs auteurs. Ainsi tous les textes religieux, philosophiques et scientifiques étaient-ils écrits en latin; mais certains genres littéraires étaient écrits exclusivement en langue d'oc ou en langue d'oïl, en galicien ou en arabo-hébreu, etc. En second lieu, certains textes étaient bi ou même trilingues, ce qui rendait problématique le sens même de leur traduction (comme aujourd'hui le Finnegans Wake de Joyce). Tel est le cas, par exemple, des récits de voyage de Marco Polo, écrits dans un mélange de français et de vénitien, ou celui (vers la fin du moyen âge) des textes de Christophe Colomb, rédigés dans un espagnol fortement teinté de portugais.

En dernier lieu, l'acte de traduire variait selon les types de textes et les diverses langues. Traduire en latin n'était pas la même chose que traduire $d u$ latin (enromanchier, volgarizzare). Traduire un ouvrage religieux n'était pas la même chose que traduire un ouvrage littéraire, juridique ou didactique. A chaque type de traduction pouvait revenir, à la limite, un nom différent.

Pour nous, et même si nous distinguons aussi des types de traduction, un seul et même terme désigne l'opération de traduire, car elle nous semble fondamentalement identique dans tous les cas, c'est-à-dire quels que soient les textes et les langues en question. Cela permet de donner une certaine unicité au concept de «traduction», même s'il est difficile, par exemple dans le cas des livres d'enfants, des scénarios de films ou des primeiro lugar, certos tipos de textos deveriam ser escritos em línguas determinadas, qualquer que fosse a nacionalidade e a língua de seus autores. Assim, todos os textos religiosos, filosóficos e científicos eram escritos em latim; mas certos gêneros literários eram escritos em língua provençal (langue d'oc) ou na língua d'oïl (língua galo-românica), em galego ou em árabe-hebraico etc. Em segundo lugar, certos textos eram bi ou trilíngues, o que tornava problemático o sentido da sua tradução (como hoje, o Finnegans Wake, de Joyce). Tal é o caso, por exemplo, dos relatos de viagem de Marco Pólo, escritos numa mistura de francês e de veneziano, o dos textos de Cristóvão Colombo (perto do fim da Idade Média), redigidos em um espanhol fortemente tingido de português.

Por último, o ato de traduzir variava segundo os tipos de texto e as diversas línguas. Traduzir em latim não era a mesma coisa que traduzir do latim (enromanchier, volgarizzare). Traduzir uma obra religiosa não era o mesmo que traduzir uma obra literária, jurídica ou didática. Cada tipo de tradução podia receber um nome diferente.

Para nós, mesmo se distinguimos também os tipos de tradução, um único termo designa a operação de traduzir, porque ela nos parece fundamentalmente idêntica em todos os casos, ou seja, quaisquer que sejam os textos e as línguas em questão. Isso permite que se dê certa unicidade ao conceito de "tradução", mesmo quando é difícil de distinguir claramente entre tradução e adaptação, como, por exemplo, no caso dos li- 
messages publicitaires, de distinguer nettement entre traduction et adaptation; même si, pour la poésie, nous avons du mal à tracer les limites de la «simple» traduction et de la recréation; même si, enfin, il est fort douteux que nous traduisions du chinois ou du japonais comme nous traduisons de l'anglais et de l'espagnol.

Le réseau langagier dans lequel opérait le «translateur» médiéval n'était donc pas identique au nôtre. Et le réseau scripturaire dans lequel s'inscrivait la traduction à cette époque était, lui aussi, sui generis: traduire n'était qu'une forme, elle-même plurielle, de l'incessant réarrangement textuel en quoi consistait une bonne partie de l'écriture médiévale.

L'acte de «traduire», comme tel, existait bien; mais, pris dans ce double réseau, il n'avait ni visage propre, ni nom unique. En conséquence, la notion de fidélité n'était pas non plus la même que la nôtre.

Cette non-délimitation (ou ce qui nous semble tel) remontait en fait à l'Antiquité grecque et romaine. Les Grecs, qui n'ont pas traduit à l'époque classique, avaient deux mots pour désigner la traduction, orale et écrite: metapherein et hermeneuein d'abord, puis, à l'époque tardive de Plutarque, metaphrazein. Les deux premiers verbes ont donné en français métaphore et herméneutique, si metaphrazein n'est pas passé dans notre langue, nous avons, très proche, $p a$ raphraser, acte avec lequel, historiquement, la traduction a entretenu des liens étroits. Si bien que les Grecs, semble-t-il, situaient la traduction dans trois domaines distincts, celui de l'activité métaphorique, celui de l'activité herméneutique (ou interprétative) et celui de la reformula- vros infantis, legendas de filmes ou mensagens publicitárias; mesmo se, para a poesia, tenhamos mal delimitados os limites da "simples" tradução e da recriação; mesmo se, enfim, seja bem duvidoso que traduzamos do chinês e do japonês da mesma forma como traduzimos do inglês e do espanhol.

A rede linguística na qual operava o "translator" medieval não era, portanto, idêntica à nossa. E a rede linguística na qual se inscrevia a tradução naquela época era, ela também, plural, com o incessante rearranjo textual que consistia uma boa parte da escrita medieval.

$\mathrm{O}$ ato de traduzir, como tal, existia; mas preso a essa dupla rede, ele não tinha nem cara própria, nem nome único. Como conseqüência, a noção de fidelidade não era a mesma que a nossa.

Essa não-delimitação (ou isso que nos parece como tal) remonta de fato à Antiguidade Greco-romana. Os gregos, que não traduziram na época clássica, tinham duas palavras para designar a tradução oral e escrita: metapherein e hermeneuein e, depois, na época tardia de Plutarco, metaphrazein. Os dois primeiros verbos deram origem no francês a métaphore [metáfora] e herméneutique [hermenêutica]. Se metaphrazein não passou à língua francesa, temos o muito próximo paraphraser [parafrasear], ato com o qual a tradução, historicamente, manteve laços estreitos. De modo que os gregos, ao que parece, situavam a tradução em três domínios distintos: os da atividade metafórica, da hermenêutica (ou interpretativa) e da reformulação. ${ }^{7}$ A tra- 
tion. ${ }^{7}$ La traduction pouvait être un cas particulier de chacune de ces activités.

Chez les Romains, le mot interpres désignait à la fois le traducteur et l'exégète. Il y avait, en latin, de très nombreux verbes pour désigner la traduction, dont les derniers furent transferre et translatare (qui désignait tout autant l'activité métaphorique). Mais, alors que la Grèce avait ignoré la traduction, Rome ftit, en Occident, son vrai lieu de naissance. $\mathrm{Au}$ début, cette activité resta sans nom (sans verbe) propre. Écoutons ce que nous dit à ce propos le grammatologue allemand Lohmann:

Le concept de traduction présuppose la possibilité de l'identité de contenu de ce qui est linguistiquement visé dans les diverses formes d'expression langagière. Ce concept de «traduction», pour être tout à fait précis, n'existe que depuis Cicéron, dans les écrits philosophiques et rhétoriques duquel nous assistons, d'une certaine manière, à la naissance de ce concept (qui représente un rapport entièrement nouveau de l'homme au langage) (...). Cela s'exprime, entre autres choses, par le fait que Cicéron ne dispose pas encore de concept verbalement fixé pour cette opération (il dit par exemple: vertere, convertere, aliquid (Latine) exprimere, verbum e verbo, ad verbum exprimere, (Graecef Latine) redderet verbum pro verbo reddere ... Le latin est donc le lieu où ce nouveau rapport de l'homme au langage s'est d'abord formé en Europe, ce pour quoi on peut le caractériser comme la première langue au sens strict du terme (c'est-à-dire une langue qui, pour ses locuteurs, est faite de «termes»non de «paroles»! -, termes qu'on se représente comme transcendant d'une certaine façon leur sens et qui, par là, sont par rapport à ce sens essentiellement «convertibles»). ${ }^{8}$ dução podia ser um caso específico de cada uma dessas atividades.

Nos romanos, a palavra interpres designava ao mesmo tempo o tradutor e o exegeta. Havia, em latim, inúmeros verbos para designar a tradução, entre os quais, os últimos foram transferre e translatare (que designavam da mesma forma a atividade metafórica). Mas, ainda que a Grécia tenha ignorado a tradução, Roma foi, no Ocidente, o seu verdadeiro lugar de nascimento. No começo, a atividade permanece sem nome (sem verbo) próprio. Escutemos o que nos diz a esse respeito o gramatólogo alemão Lohmann:

O conceito de tradução pressupõe a possibilidade da identidade de conteúdo disso que é linguisticamente pretendido nas diversas formas de expressão lingüística. Esse conceito de "tradução", para ser bem específico, só existe depois de Cícero, nos escritos filosóficos e retóricos nos quais assistimos, de certa maneira, ao nascimento desse conceito (que representa uma ligação inteiramente nova do homem com a linguagem) (...). Isso se exprime, entre outras coisas, pelo fato de que Cícero não dispunha mais do conceito verbalmente fixado por essa operação (ele disse, por exemplo: vertere, convertere, aliquid (latino) expremire, verbum e verbo, ad verbum exprimere, (Graece Latine) reddere... O latim é, portanto, o lugar onde essa nova ligação do homem com a linguagem é então formada na Europa, é por isso que podemos caracterizá-lo como a primeira língua no sentido estrito do termo (ou seja, uma língua que, por seus falantes, é feita de "termos" - não de "palavras"! -, termos que se representam como transcendentes de certa forma de seus significados e que, desse modo, são, em relação a este sentido, essencialmente conversíveis). ${ }^{8}$

\footnotetext{
${ }^{7}$ G. Mailhos, les Tours de Babel (Mauvezin, Trans-Europ-Repress, 1985), p. 256. 28.

${ }^{8}$ J. Lohmann, Philosophie unci Sprachwissentschaft (Berlin, Dunker und Humblot, 1965), p. 85.
} 
Le terme latin qui s'imposa à la fin de l'Antiquité et se transmit au moyen âge, c'est translatio, avec le verbe correspondant translatare. Mais ce terme, à Rome, avait à son tour maintes significations. Il ne désignait pas seulement la traduction interlangues. Comme le dit Lusignan:

Translatio peut signifier en latin: le transport physique d'objets, le déplacement de personnes, le transfert de droit ou de juridiction, le transfert métaphorique, le déplacement d'idées et finalement la traduction. La translatio peut désigner aussi bien le déplacement physique que le transfert symbolique, elle peut connoter le transport tout autant que la prise de possession. ${ }^{9}$

Toutefois, cette multiplicité sémantique s'enracinait dans une signification fondamentale: la translatio était avant tout un mouvement de transfert. C'est en vertu de cette pluralité de sens et de cette signification fondamentale que le moyen âge fidèle en cela à l'esprit latin - a pu développer le thème de la translatio studii. Mais, si translation finit par prédominer dans les textes médiévaux, il ne s'imposa jamais comme un terme unique. C'est seulement au début du XVIe siècle qu'apparaît en France un nouveau terme pour désigner, unitairement cette fois, l'acte de «traduire».

Ce terme, c'est notre mot traduction. Lui aussi d'origine latine, il nous est venu d'Italie. C'est en effet un Italien qui l'aurait employé pour la première fois, sur la base d'une interprétation erronée du verbe latin traducere. Si bien que le mot que nous employons aujourd'hui pour désigner l'acte de traduire vient... d'une erreur
O termo latino que vai se impor no fim da Antiguidade e passar à Idade Média é translatio, com o verbo correspondente translatare. Mas esse termo, em Roma, tinha, por sua vez, muitos significados. Não designava somente a tradução interlingual. Como diz Lusignan:

Translatio pode significar em latim o transporte físico de objetos, o deslocamento de pessoas, a transferência de direito ou de jurisdição, a transferência metafórica, o deslocamento de ideias e, finalmente, a tradução. A translatio pode designar tanto o deslocamento físico como a transferência simbólica, pode conotar o transporte como o ato de posse. ${ }^{9}$

De toda forma, essa multiplicidade semântica se enraizava numa significação fundamental: a translatio estava à frente de todo um movimento de tranferência. É em virtude dessa pluralidade de sentidos $e$ dessa significação fundamental que a Idade Média - fiel nisso ao espírito latino pôde desenvolver o tema da translatio studii. Mas, se translation termina predominando nos textos medievais, o termo jamais será imposto como único. É somente no início do século XVI que aparece na França um novo termo para designar, desta vez, unitariamente, o ato de "traduzir".

Esse termo é a nossa palavra traduction [tradução]. Ele, também de origem latina, veio até nós via Itália. É de fato um italiano que o havia empregado pela primeira vez, tendo como base uma interpretação errônea do verbo latino traducere. Desta forma, a palavra que empregamos hoje para designar o ato de traduzir vem

${ }^{9}$ S. Lusignan, Parler vulgairement (Paris/Montréal, Vrin/ Presses de l'Université de Montréal, 1986), pp. 158-159. 
de traduction. Le fait est assez notable pour mériter d'être raconté dans le détail. ${ }^{10}$

Le verbe traduire existait déjà en France au XVe siècle, mais seulement dans le domaine juridique, où il s'est maintenu jusqu'à aujourd'hui, comme lorsque nous disons: «il a été traduit en justice». Traduire, ici, vient effectivement du verbe latin traducere, qui a un sens matériel, et n'a rien à voir avec la «traduction».

C'est Leonardo Bruni qui aurait rendu par le toscan tradotto le participe passé traductum employé par un auteur latin, Aulu Gelle. Seulement, pour ce dernier, traductum ne signifiait pas «traduit», mais «transporté». Dans le passage où il emploie ce participe passé, il est question du transfert d'un vieux mot grec en latin, donc de ce que nous appelons un emprunt. C'est-à-dire du contraire, en principe, d'une traduction.

L'usage d'employer tradurre comme synonyme de translatare se répandit chez les humanistes italiens et, de là, passa en France et dans le reste de l'Europe - l'Angleterre exceptée. Le verbe traduire est attesté dans un ouvrage paru en 1509, d'un certain «maistre Jehan Divry», qui l'emploie en même temps que translater. Le titre de cet ouvrage indique:

Le Catalogue de Salomon et de Marcolphus translaté en français, avec les ditz des sept sages et d'aultres philosophes du grece traduits de grec en françois $p$ maistre Jehan Diuery. ${ }^{11}$ de um erro de tradução. O fato é notável o bastante e merece ser contado em detalhes. ${ }^{10}$

$\mathrm{O}$ verbo traduire já existia na França no século $\mathrm{XV}$, mas somente no domínio jurídico, onde se mantém até hoje, como quando dizemos: "Il a éte traduit en justice" [Ele foi conduzido aos tribunais]. Traduire, aqui, vem efetivamente do verbo latino traducere, que tem um sentido material, e não tem relação com a "tradução".

Foi Leonardo Bruni quem traduziu para o toscano tradotto o particípio passado traductum empregado por um autor latino, Aulo Gélio. Só que para esse último, traductum não significava "traduzido", mas "transportado". Na passagem em que ele emprega esse particípio passado, ele menciona a transferência de uma velha palavra grega ao latim, então, fala disso que nós chamamos de empréstimo. Ou seja, é, em princípio, o contrário de uma tradução.

O emprego de tradurre como sinônimo de translatare se difundiu entre os humanistas italianos e, então, passou à França e ao restante da Europa - exceto à Inglaterra. $\mathrm{O}$ verbo traduire [traduzir] é confirmado em uma obra de 1509 , de certo "mestre Jehan Dirvy", que o emprega junto com translater [translatar]. O título dessa obra indica:

O catálogo de Salomão e de Marcolphus traduzido em francês com as máximas de sete sábios e de outros filósofos da Grécia traduzidos do grego ao francês pelo mestre Jehan Diuery (sic). ${ }^{11}$

\footnotetext{
${ }^{10}$ Paul Chavy, «Depuis quand traduit-on en français?» Bibliothèque d'Humanisme et Renaissance, tome XLIV (Genève, Lib. Droz, 1982), pp. 361-362.

${ }^{11}$ Paul Chavy, op. cit.
} 
À partir de cette date, le mot traduction (avec le verbe correspondant) va peu à peu évincer translation. À tel point qu'en 1679 le dictionnaire de Richelet estime que translater n'est qu'

un vieux mot qui signifie traduire et qui, tout au plus, ne peut trouver sa place que dans l'ancien burlesque et dans le comique. ${ }^{12}$

Pourquoi le mot traduction s'est-il imposé, alors qu'il venait d'un mot latin ne signifiant pas «traduction»? Certains historiens nous disent que la Renaissance l'a préféré parce qu'il était plus «dynamique» et plus «expressif» que translation. Ceci appelle plusieurs remarques. Traductio appartient à une famille sémantique très différente de celle de translatio. Cette famille de mots a fourni, à partir de ductio et du verbe ducere (conduire), des termes comme induction, déduction, réduction, séduction, production, et reproduction. Michel Serres a bien noté cet état de choses (de mots):

Nous ne connaissons les choses que par les systèmes de transformation des ensembles qui les comprennent. Au minimum, ces systèmes sont quatre. La déduction, dans Taire logico-mathématique. L'induction, dans le champ expérimental. La production, dans les domaines de pratique. La traduction, dans l'espace des textes. Il n'est pas complètement obscur qu'ils répètent le même mot. ${ }^{13}$

Alors que la translation met l'accent sur le mouvement de transfert ou de transport, la traduction,
A partir dessa data, a palavra tradução (com seu verbo correspondente) vai pouco a pouco destituir translação, a tal ponto que em 1679 , o dicionário de Richelet afirma que translação não é mais que

uma velha palavra que significa traduzir e que, de mais a mais, só pode encontrar seu espaço na antiga burlesca e no cômico. ${ }^{12}$

Por que a palavra tradução se impôs, visto que derivava de uma palavra latina que não significava "tradução"? Alguns historiadores nos dizem que o Renascimento a preferiu porque ela era mais "dinâmica" e "expressiva" do que translação. Isso clama por várias considerações. Traductio pertence a uma família semântica bastante diferente daquela de translatio. Essa família de palavras forneceu, a partir de ductio e do verbo ducere (transportar, conduzir), termos como induction [indução], déduction [dedução], reduction [redução], séduction [sedução], production [produção] e reproduction [reprodução]. Michel Serres percebeu esse estado de coisas (de palavras):

Somente conhecemos as coisas por meio dos sistemas de transformação dos conjuntos que os formam. Esses sistemas são no mínimo quatro. A dedução, na área lógicomatemática; a indução, no campo experimental; a produção, nos domínios da prática e a tradução, no âmbito dos textos. Não é completamente estranho que eles repitam a mesma palavra. ${ }^{13}$

Enquanto a translação põe em evidência o movimento de transferência ou de transporte, a tradução

\footnotetext{
${ }^{12}$ Paul Chavy, op. cit.

${ }^{13}$ Michel Serres, la Traduction (Paris, éd. de Minuit, 1974), p. 9.
} 
elle, souligne plutôt l'énergie active qui préside à ce transport, justement parce qu'elle renvoie à ductio et $d u$ cere. La traduction est une activité qui a un agent, alors que la translation est un mouvement de passage plus anonyme. Tous les mots formés à partir de ductio supposent des agents. Et c'est justement parce que l'opération traduisante est conçue, à partir de la Renaissance, comme un acte, et comme un acte spécifique, qu'on se met à l'appeler traduction.

Dans les siècles suivants, on verra les autres composés de auction acquérir les uns après les autres leurs lettres de noblesse. Déjà, à cette époque, réduction est un terme fondamental de l'alchimie. Au XVIIe siècle, la déduction devient une catégorie fondamentale du savoir. Au même siècle, l'économie, la biologie, puis la technologie, font de la production et de la reproduction des catégories tout aussi fondamentales.

On remarquera, avec Serres, que l'élément commun à tous ces termes est non seulement l'activité, mais la force transformante. D'une certaine façon, tous les composés de duction sont, sur cette base, définissables les uns par les autres: la traduction est une reproduction et une production, voire une réduction, mais production, reproduction, induction et déduction peuvent être définies (à la limite) en termes de «traduction».

Évincé par traduction, le mot translation a certes survécu: en anglais, d'abord (et nous allons y venir tout de suite), en français, également, mais en perdant tout lien avec l'activité de traduction. Jusqu'au XIXe siècle, il est resté synonyme de «transport»; de nos jours, il ne désigne plus sublinha bem mais a energia ativa que preside esse transporte, justamente porque remete a ductio e a $d u$ cere. A tradução é uma atividade que tem um agente, enquanto a translação é um movimento de passagem mais anônimo. Todas as palavras formadas a partir de ductio supõem agentes. E é justamente por isso que a operação tradutória é concebida a partir do Renascimento como um ato, e como um ato específico, que começamos a chamar de tradução.

Nos séculos seguintes, veremos as demais palavras compostas a partir de duction adquirirem uma após a outra os seus títulos de nobreza. Já na época, réduction [redução] é um termo fundamental da alquimia. No século XVII, a déduction [dedução] se torna uma categoria fundamental do saber. No mesmo século, a economia, a biologia, depois a tecnologia, encontram na production [produção] e na reproduction [reprodução] as suas categorias fundamentais.

Veremos, com Serres, que o elemento comum a todos esses termos não é somente a atividade, mas a força transformadora. De certa forma, todas as palavras compostas por duction [dução] são definíveis uma pelas outras: a tradução é uma reprodução e uma produção, inclusive uma redução, mas também produção, reprodução, indução e dedução podem ser definidas (em última instância) em termos de "tradução".

Eliminada por tradução, a palavra translação tem certa serventia: em inglês, primeiramente (veremos isso em seguida), e em francês, também, mas perdendo toda a ligação com a atividade tradutória. Até o século XIX, manteve-se como sinônimo de "transporte" e, hoje em dia, 
guère qu'un certain type de déplacement géométrique.

Le passage de la translation à la traduction nous conduit à la réflexion suivante: le réseau langagier dans lequel est pris, à chaque fois, l'ensemble des termes désignant l'acte de traduire dans chaque grande langue occidentale peut nous révéler comment une culture pense cet acte et détermine à la fois sa nature et sa place.

Cela apparaîtra clairement si nous comparons brièvement le français traduction, l'anglais translation et l'allemand Übersetzung.

Le Webster's indique pour translation au moins quatre acceptions de base: l'acte de traduire et son résultat, le transport matériel, la transformation, ou transmutation, ou conversion, et enfin le transfert de droits. Pour le verbe to translate, les acceptions sont encore plus nombreuses.

Le Robert, par contre, ne fournit que deux acceptions pour traduction: l'acte de traduire et son résultat, la transposition, comme lorsqu'on dit: «il a bien traduit les idées de l'auteur». Pour le verbe traduire s'ajoute l'acception juridique mentionnée plus haut. L'existence de cette acception modifie en fait les autres: «traduire un livre», en français, c'est toujours un peu le «traduire» devant le «tribunal» de notre langue et de notre goût.

Le champ sémantique de translation n'est pas seulement plus riche que celui de traduction et plus lié à la translatio latine: grâce à la polysémie de ce terme, la langue anglaise peut intégrer l'opération traduisante au champ plus vaste des transforma- não designa mais que um tipo de deslocamento geométrico.

A passagem da translação para a tradução nos leva à seguinte reflexão: a rede de linguagem na qual se insere sempre o conjunto dos termos designando $o$ ato de traduzir em cada grande língua ocidental pode nos revelar como uma cultura pensa esse ato e determina ao mesmo tempo a sua natureza e o seu lugar.

Isso vai aparecer de forma clara se comparamos brevemente o francês traduction [tradução], o inglês translation [translação] e o alemão Übersetzung [tradução].

O Webster's indica no mínimo quatro acepções de base para translation: o ato de traduzir e o seu resultado, o transporte material, a transformação, ou transmutação, ou conversão, e finalmente a transferência de direitos. Para o verbo to translate, as acepções são ainda mais numerosas.

O dicionário Le Robert, no entanto, só fornece duas acepções para traduction [tradução]: o ato de traduzir e o seu resultado, a transposição, como por exemplo "ele traduziu bem as idéias do autor". Para o verbo traduire [traduzir], acrescenta-se a acepção jurídica mencionada há pouco. A existência dessa acepção modifica na verdade as outras: "traduzir um livro", em francês, é sempre um pouco como traduzi-lo frente ao tribunal da língua e do gosto franceses.

O campo semântico de translation [translação] não é somente mais rico que o de traduction [tradução] e mais ligado à translatio latina: graças à polissemia desse termo, a língua inglesa pode integrar a operação tradutória ao campo mais vasto das 
tions, et, réciproquement, interpréter celui-ci en termes de «traduction». Cela, le français ne peut le faire qu'en employant le mot traduction métaphoriquement.

Que l'anglais ait conservé le latin translatio n'est nullement un hasard. Cela est lié à la façon dont la culture anglo-saxonne a conçu, dès le moyen âge, et sa langue, et le langage en général: comme un système de «termes» conventionnels servant à «communiquer». Autant il est peu rigoureux de dire que la communication est un acte de «traduction», autant il est exact de dire qu'elle est un acte de «translation». Nous avons vu qu'Oresme, le créateur du terme français communication, était aussi le théoricien de la translatio studii. Et cela est logique: car la translatio studii est un processus de communication. Mais c'est seulement la culture anglo-saxonne qui, au fil des siècles, a fait de sa langue une langue communicationnelle. Elle l'a fait méthodiquement, en la dotant d'un énorme stock terminologique, et en créant, dès le XVIe siècle, un tissu discursif de base, le plain style, apte à fonctionner comme un médium de transmission polyvalent.

Ainsi la langue anglaise est-elle essentiellement translative, et c'est pourquoi translation reste pour elle un signifiant central. À ce titre, elle a conquis une triple position: elle est devenue le principal médium de création terminologique, c'est-à-dire de signifiants spécialisés fondamentalement convertibles ou commutables; sur cette base, elle est devenue le principal médium de communication technologique à l'échelle mondiale; enfin, elle est devenue le principal médium de transmission des textes transformações, e, reciprocamente, interpretá-lo em termos de traduction [tradução]. O francês só pode fazê-lo se usar a palavra traduction [tradução] de forma metafórica.

$O$ fato de o inglês ter conservado translatio não é por acaso. Isto é ligado à maneira da cultura anglosaxônica ter concebido, desde a Idade Média, a sua língua e a linguagem em geral como um sistema de "termos" convencionais servindo para "comunicar-se". Se for pouco rigoroso dizer que a comunicação é um ato de "tradução", é exato dizer que ela é um ato de "translação". Vimos que Oresme, o criador do termo francês communication [comunicação], também foi o teórico da translatio studii. E isso é lógico: pois a translatio studii é um processo de comunicação. Mas é somente a cultura anglosaxônica que, ao longo dos séculos, fez com que sua língua se tornasse uma língua comunicacional. Ela o fez de forma metódica, lhe dando um enorme estoque terminológico, e criando, desde o século XVI, um tecido discursivo básico, o plain style [estilo simples] apto a funcionar como meio de transmissão polivalente.

Assim, a língua inglesa é essencialmente translativa, e por isso, translation [translação] continua sendo um significante central. Neste sentido, ela conquistou uma posição tripla: tornou-se o principal meio de criação terminológica, isto é, de significantes especializados fundamentalmente conversíveis ou comutáveis; baseando-se nisso, ela se tornou o principal meio de comunicação tecnológica em nível mundial; e, por fim, ela se tornou o principal meio de transmissão de textos escritos nas 
écrits dans les langues dites «lointaines», comme le chinois, l'indien ou le japonais. Dans les deux premiers cas, elle fonctionne comme langue modèle pour toutes les autres langues voulant devenir des langues de communication. Dans le dernier, elle fonctionne comme médium d'occidentalisation des textes extrêmeorientaux, dont elle «convertit» les signifiés pour les faire circuler.

Si l'anglais est devenu la langue translative mondiale, c'est primordialement parce qu'il se conçoit comme un pur système de signes permutables. D'où une conséquence: toute «traduction», dans le domaine anglo-saxon, s'effectue nécessairement dans l'horizon de la «translation» telle que l'avait définie Oresme. Plus précisément, la langue anglaise ne traduit pas, elle translate, c'est-àdire fait circuler des «contenus» qui, en eux-mêmes, sont de nature translinguistique. C'est bien ainsi qu'Hofstadter, l'auteur nord-américain de Godel Escher Bach, considère la version française de son propre ouvrage:

Qui lira les éditions anglaises et françaises de GEB (...) pourra distinguer ce qui est «glissable», ou inessentiel, de ce qui est ferme et essentiel. Comme cela, il découvrira un noyau inglissable: le GEB «platonicien», le GEB idéal, flottant majestueusement dans un espace éthéré, indépendant de toute langue terrestre. ${ }^{14}$

La translation suppose donc des contenus indépendants de leur «robe» langagière et, inversement, le concept de langage propre à la culture anglosaxonne (qui l'a du reste inventé) pose toute langue comme un pur línguas ditas "longínquas" como o chinês, o híndi ou o japonês. Nos dois primeiros casos, ela funciona como língua modelo para todas as outras línguas querendo se tornar línguas de comunicação. No último caso, ela funciona com meio de ocidentalização dos textos do extremo oriente cujos significantes ela converte para que circulem.

Se o inglês se tornou a língua translativa mundial, é principalmente porque se concebe como um simples sistema de signos permutáveis. Daí uma conseqüência: toda "traduction" [tradução] na área anglo-saxônica se efetua necessariamente no horizonte da "translation" [translação] tal com Oresme a havia definido. Mais precisamente, a língua inglesa não traduz, ela translata, isto é, ela faz circular os "conteúdos" que são de natureza translinguística. É assim que Hofstadter, o autor norte-americano de Godel Escher Back [Um entrelaçamento de gênios brilhantes ] considera a versão francesa do seu próprio livro:

Quem ler as edições inglesas e francesas de GEB (...) poderá distinguir o que é "desviante" ou desnecessário, do que é firme e essencial. Assim, descobrirá um núcleo não desviante; o GEB platônico, o GEB ideal, flutuando majestosamente num espaço etéreo, independente de qualquer língua terrestre. $^{14}$

A translação supõe conteúdos independentes da sua "roupa" de linguagem e, ao contrário, o conceito de linguagem própria à cultura anglosaxônica (que, aliás, ele inventou) coloca toda língua como um puro meio

\footnotetext{
${ }^{14}$ Hofstadter, Godel Escher Bach (Paris, Interéditions, 1985), p. XXV.
} 
médium translatif.

Le cas de l'allemand est bien différent. Cette langue possède en effet au moins deux verbes pour désigner l'acte de traduire: übersetzen et übertragen. Übersetzen, littéralement «poser au-delà», est la traduction de traduction et signifie en effet «traduire». Mais pas seulement. Der Fahrmann hat uns übergesetzt veut dire: le passeur nous a fait franchir la rivière. Übersetzen signifie aussi «encombrer», «alourdir». ${ }^{15}$ Übertragen, de son côté, veut aussi dire «traduire», mais également «transférer» et «transporter». Dans l'allemand de Freud, Übertragung signifie le «transfert» (analytique). L'allemand a donc pour la traduction deux termes appartenant à des réseaux sémantiques différents dont les acceptions, additionnées, dépassent celles de la translatio latine et de la translation anglo-saxonne.

Ce n'est pas tout. Übersetzung est un mot formé de deux signifiants, über et Setzung, et c'est un concept différent de la «traduction» qui surgit: un tel mouvement d'accentuation se retrouve aussi bien au XVIIIe siècle chez Herder qu'au XXe chez Heidegger. ${ }^{16}$

Pour la langue allemande, la «traduction» n'est pas un mouvement de translation des signifiés, ni l'énergie présidant à ce mouvement: elle est cette opération par laquelle, en un double mouvement, quelque chose d'étranger est posé au-delà de luimême (übergesetzt), dans la langue traduisante, et quelque chose de pro- translativo.

O caso do alemão é bem diferente. Essa língua tem de fato ao menos dois verbos para designar o ato de traduzir: Übersetzen e Übertragen. Übersetzen, literalmente, "colocar além" é a tradução de tradução e significa de fato "traduzir". Mas não é só isso. Der Fahrmann hat uns übergesetzt quer dizer: o atravessador nos fez passar o rio. Übersetzen significa também "obstruir", "tornar pesado". ${ }^{15}$ Übertragen, por sua vez, também significa "traduzir", mas ainda "transferir" e "transportar". $\mathrm{Na}$ língua de Freud, Übertragung significa a "transferência" (analítica). O alemão tem, portanto, para designar a "tradução" dois termos pertencendo a campos semânticos diferentes cujas acepções, juntas, ultrapassam as da translatio latina e da translation anglo-saxônica.

Há mais. Übersetzung é uma palavra formada por dois significantes, über e Setzung, e é um conceito diferente da "tradução": tal movimento de acentuação se encontra tanto no século XVIII em Herder quanto no século XX em Heidegger. ${ }^{16}$

Para a língua alemã, a "tradução" não é um movimento de translação dos significados, nem a energia presidindo esse movimento: ela é a operação pela qual, num movimento duplo, algo estrangeiro é colocado além dele próprio (übergesetzt), na língua traduzinte, e algo próprio é deportado, ou melhor, se deporta

\footnotetext{
${ }^{15}$ G. Mailhos, op. cit., p. 260.

${ }^{16}$ Cf. Martin Heiddegger, Was heisst Denken? (Niemeyer, 1954), p. 140: «Dieses aber Übersetzen ist nur möglich als Übersetzen», «mais cette Tra-duction n'est possible que comme Tra-duction» (trad. G. Granel, Qu 'appelle-t-on penser?, Paris, PUF, 1959), p. 213.
} 
pre est déporté, ou plutôt se déporte (setzt sich über) au-delà de lui-même, dans l'étranger. «Traduire» est aussi bien «traduire de...» que «se traduire vers...»

D'où vient, sans doute, que la culture allemande soit, historiquement, la plus grande culture-de-latraduction en Europe. L'Allemagne a produit les réflexions les plus fondamentales de l'Occident sur l'acte de traduire, et ces réflexions ne cessent de creuser, depuis les horizons les plus divers, l'essence de ce double mouvement inscrit dans la structure même du mot Übersetzung. Là où l'anglais pointe vers la translativité générale des contenus, l'allemand pointe vers l'intertraductivité des langues.

Entre la puissance translative de l'anglais et la puissance traductive de l'allemand, qu'en est-il de la langue française et de son rapport à la «traduction»?

Plus délimitée (voire limitée) que la translation et Übersetzung, la traduction met l'accent - conformément à ce que ce mot dit originairement - sur l'action de traduire: or, cette action, comme toutes celles des composés de duction, est par essence transformante. Rien d'étonnant, dès lors, si c'est la culture française qui a créé la forme de traduction la plus «libre» de l'histoire occidentale: la «belle infidèle». Si la langue allemande conçoit la «traduction» comme un jeu réciproque du propre et de l'étranger, si la langue anglaise la conçoit comme une mise en circulation de signifiés hors de toute référence au proche et à l'étranger, la langue française, elle, voit dans l'acte de traduire l'acclimatation adaptatrice de l'étranger. (setzt sich über) além dele mesmo, no estrangeiro. "Traduzir" é tanto "traduzir de..." como "traduzir para...".

Daí, talvez, o fato de que a cultura alemã seja historicamente a maior cultura-de-tradução na Europa. A Alemanha produziu as mais fundamentais reflexões do Ocidente sobre o ato de traduzir, e essas reflexões não deixam de aprofundar, desde os mais diversos horizontes, a essência desse duplo movimento inscrito na estrutura mesma da palavra Übersetzung. Quando o inglês aponta em direção da translatividade geral dos conteúdos, o alemão aponta em direção das línguas.

Entre a potência translativa do inglês e a potência tradutória do alemão, o que dizer da língua francesa e da sua relação com a "tradução"?

Mais delimitada (até limitada) que a translation e a Übersetzung, a tradução tem seu foco - conforme o que essa palavra fala na origem - na ação de traduzir: ora, essa ação, como todas compostas com ção, é por essência transformadora. Sem espanto daí, se a cultura francesa criou a forma de tradução mais "livre" da historia ocidental: a "bela infiel". Se a língua alemã concebe a "tradução" como um jogo recíproco do próprio e do estrangeiro, se a língua inglesa a concebe como uma circulação de significados fora de qualquer referência ao próximo ou ao estrangeiro, a língua francesa vê no ato de traduzir a aclimatação adaptadora do estrangeiro. 
S'il en est ainsi - et indépendamment du fait que ces différentes traditions de traduction peuvent s'influencer mutuellement et dialoguer -, il faut reconnaître qu'un AngloSaxon, un Allemand et un Français ne pensent pas - ne peuvent pas penser - la «traduction» de la même manière. Traduction, translation et Übersetzung ne «se traduisent» pas mutuellement (sauf en surface). Croire le contraire serait nier l'impérieuse puissance des signifiants sur l'existence humaine.

Si l'acte de traduire devient au XVIe siècle, et dans toute l'Europe, malgré les différences que nous venons d'analyser, une opération délimitée, il ne s'ensuit nullement que cette délimitation soit totale. D'abord, parce que le mode de pensée médiéval se maintient longtemps, mélangé au mode de pensée des Temps modernes. Le traducteur Denis Sauvage range encore les traducteurs parmi les

commentateurs, restaurateurs de livres corrompus et tels autres qui sont subjects à suyvre les traces d'autruy. ${ }^{17}$

Mais l'accent s'est légèrement déplacé: au lieu d'appartenir à l'exégèse et au ré-agencement des «textes préalables», la traduction vient désormais se ranger dans une nouvelle catégorie d'écrits avec le commentaire: celle des textes considérés comme seconds par rapport à des textes con-
Se for assim - e independentemente do fato de que essas diferentes tradições de tradução podem influenciar-se e dialogar -, é preciso reconhecer que um anglo-saxão, um alemão e um francês não pensam - e não podem pensar - a "tradução" da mesma maneira. Traduction, translation e Übersetzung não "se traduzem" mutuamente (a não ser em superfície). Acreditar no contrário seria negar a potência absoluta dos significantes sobre a existência humana.

Se o ato de traduzir se torna no século XVI, e em toda a Europa, apesar das diferenças que acabamos de analisar, uma operação delimitada, ao que parece essa delimitação não é total. Primeiro porque o modo de pensar medieval se manteve, durante muito tempo, misturado ao modo de pensar dos tempos modernos. O tradutor Denis Sauvage considera os tradutores como os

commentateurs, restaurateurs de livres corrompus et tels autres qui sont subjects a suyvre les traces d'autruy. ${ }^{17}$

[comentaristas, restauradores de livros corrompidos e outros que estão propensos a seguir os passos de outrem.]

Mas o tom deslocou-se ligeiramente: em vez de pertencer à exegese e ao pré-agrupamento dos "textos prévios", a tradução está se incluindo numa nova categoria de escritos junto ao comentário: a dos textos considerados como segundos em relação a textos considerados como

\footnotetext{
${ }^{17}$ L. Guillerm, op. cit., p. 9.
} 
sidérés comme premiers. Au moyen âge, les notions d'original et d'auteur, telles que nous les connaissons, n'existaient pas. C'est à la Renaissance qu'elles font leur apparition, et la traduction devient dès lors ce qu'elle est encore aujourd'hui pour notre Droit: un dérivé.

La délimitation opérée au XIVe siècle est d'autant moins totale que la Renaissance range tout de suite la traduction dans un genre plus vaste, couvrant tout le champ de l'écrit: Yimitation. Pour cette époque, tout texte est fondamentalement imitation d'autres textes, passés ou contemporains, textes qu'en imitant, on égale ou, si possible, on dépasse. Imiter n'est pas ré-agencer. C'est bien faire œuvre originale, mais en s'appropriant les thèmes et les formes d'autres œuvres. Ainsi la Franciade de Ronsard est-elle une imitation de / 'Iliade, l'Heptaméron de Marguerite de $\mathrm{Na}-$ varre une imitation du Décaméron de Boccace.

Mais l'imitation peut prendre des formes multiples. Il y a des imitations littérales et des imitations libres. Par exemple, le Livre IV de l'Enéide de Virgile, qui chante les amours de Didon et d'Énée, donne lieu en France au XVIe siècle à deux types d'imitation: les traductions de ce Livre, comme celles de du Bellay, et les œuvres originales, qui reprennent la même thématique et les mêmes personnages, comme Didon se sacrifiant de Jodelle. La traduction est fondamentalement une imitation littérale, puisqu'elle ne vise qu'-à reproduire l'original «tel quel». La pièce de Jodelle est une imitation libre.

Toutefois, la distinction entre les deux modes d'imitation reste flottante, parce que la traduction peut primeiros. Na Idade Média, as noções de original e de autor, assim como as conhecemos, não existiam. É no Renascimento que elas aparecem, e a tradução se torna desde então o que ela ainda é hoje para nosso Direito: um derivado.

A delimitação ocorrida no século XIV não é tão total, pois o Renascimento integra a tradução dentro de um gênero mais vasto, cobrindo todo o campo da escrita: a imitação. Para essa época, todo texto é fundamentalmente imitação de outros textos, passados ou contemporâneos, textos que ao imitá-los, podem ser igualados ou até ultrapassados. Imitar não é reagrupar. Tal texto pode ser original, mas somente ao se apropriar dos temas e das formas de outras obras. Portanto, a obra Franciade de Ronsard é uma imitação da Ilíada, o Heptameron da Marguerite de Navarre, uma imitação do Decameron de Boccaccio.

Mas a imitação pode assumir muitas formas. Existem imitações literais e imitações livres. Por exemplo, o Livro IV da Eneida de Virgílio, que canta os amores de Dido e Enéias, traz, na França no século XVI, dois tipos de imitação: as traduções deste Livro, como a de du Bellay, e as obras originais que retomam a mesma temática e os mesmos personagens, como Dido se sacrifican$d o$, de Jodelle. A tradução é basicamente uma imitação literal, uma vez que visa apenas a reproduzir o original "como está". A peça de Jodelle é uma imitação livre.

No entanto, a distinção entre os dois modos de imitação permanece vaga porque a tradução em si pode 
elle-même être plus ou moins littérale. Si Ton compare la version que du Bellay a donnée du vers 570 du Livre IV de l'Enéide

Ainsi parlant l'image de Mercure S'entremesla parmy la nuict obscure. ${ }^{18}$

au vers latin

Sic fatus nocti se immiscuit atrae $e^{19}$

et à la traduction moderne de Klossowski: ténèbres ${ }^{20}$,

Ayant dit, sa forme se dissipe dans les on devra convenir que du Bellay a procédé plus en imitateur libre qu'en imitateur littéral: sa traduction propose deux vers pour un, sans parler de la rime inexistante dans l'original.

Pendant tout le XVIe siècle, le statut de la traduction, en tant qu'espèce du genre «imitation», oscille. Certains y voient la forme suprême de l'imitation. Peletier déclare que

la plus vraie espèce d'imitation, c'est de traduire. Car imiter n'est autre chose que vouloir faire ce que fait un autre: ainsi que fait le Traducteur. ${ }^{21}$

D'autres — de plus en plus nombreux - y voient une activité non seulement seconde, mais «servile». «Servile», parce que le traducteur, comme le dit Peletier luimême ser mais ou menos literal. Se compararmos a versão que du Bellay fez do verso 570 do Livro IV da Eneida

Assim falando a imagem de Mercúrio Mesclou-se entre a noite obscura. ${ }^{18}$

Ao verso latim

Sic fatus nocti se immiscuit atrae ${ }^{19}$

e à tradução moderna de Klossowski:

Dito isto, sua forma se dissipa na es-
curidão $^{20}$

temos de concordar que du Bellay se comportou mais como imitador livre do que com o imitador literal: sua tradução propõe dois versos no lugar de um, sem falar da rima inexistente no original.

Ao longo do século XVI, o estatuto da tradução, enquanto espécie do gênero "imitação" varia. Alguns a vêem como a mais elevada forma de imitação. Peletier diz

o verdadeiro tipo de imitação é traduzir. Porque a imitação não é outra coisa que querer fazer o que o outro faz: assim o faz o Tradutor $^{21}$.

Outros - cada vez mais numerosos - a vêem como uma atividade não só secundária, mas "servil". "Servil", porque o tradutor, como Peletier o declarou

\footnotetext{
${ }^{18}$ Du Bellay, Euvres poétiques (Paris, Nizet, 1931), p. 297.

${ }^{19}$ L'Enéide (Paris, éd. des Belles-Lettres, 1962), p. 186.

${ }^{20}$ P. Klossowski, l'Enéide (Paris, Gallimard, 1964), p. 113.

${ }^{21}$ L. Guillerm, op. cit., p. 20.
} 
s'asservit non seulement à l'invention d'autrui, mais aussi à la Disposition; et encore à l'Elocution tant qu'il peut. ${ }^{22}$

Mais qu'elle soit considérée comme l'espèce la plus haute de l'imitation (donc comme son modèle) ou comme son espèce la plus basse, elle fait maintenant partie d'un nouveau réseau scripturaire où elle se distingue en tant que telle. Ce classement de la traduction à l'intérieur d'un genre plus vaste était inconnu des Anciens et des Médiévaux, puisque la traduction relevait pour eux de registres totalement hétérogènes.

Les époques ultérieures ont repris ce mode de classement, mais en changeant à chaque fois le genre en question. À la fin du XVIIIe siècle, la traduction devient une espèce de la critique herméneutique. $\mathrm{Au} \mathrm{XXe}$ siècle, elle tend à être définie soit comme un certain type de "production» textuelle, soit comme un certain type de «contact» linguistique. Ce qui explique qu'elle relève pour nous, selon le critère adopté, tantôt du domaine de la poétique, tantôt du domaine de la «science» du langage.

Dans tous les cas, cette subordination de la traduction à un genre plus vaste s'est avérée dangereuse pour elle. Car, à chaque fois, elle risque de n'être considérée que comme une sous-imitation, une sous-critique, une sous-écriture ou de la simple «linguistique appliquée».

Existe-t-il une manière de définir la traduction à partir d'elle-même, de la définir comme une activité spécifique? La question, aujourd'hui, doit être posée.

En tout cas, le XVIe siècle marque un tournant fondamental: escraviza-se, não só frente à invenção dos outros, mas também frente à Disposição; e ainda à Elocução o quanto pode ${ }^{22}$.

Mesmo que ela seja considerada como a maior forma de imitação (assim como o seu modelo) ou como a sua menor forma, faz agora parte de uma nova rede de escritura onde se distingue como tal. Essa inserção da tradução dentro de um gênero mais amplo era desconhecida dos antigos e dos medievos, uma vez que a tradução para eles dizia respeito a registros completamente heterogêneos.

Os períodos ulteriores retomaram esse modo de classificação, mas mudando cada vez o gênero em questão. No final do século XVIII, a tradução torna-se uma espécie de crítica hermenêutica. No século XX, tende a ser definida ora como certo tipo de "produção" textual, ora como algum tipo de "contato" linguístico. O que explica para nós que a tradução depende, de acordo com o critério adotado, ora da área poética ora da "ciência" da linguagem.

Em todo caso, a subordinação da tradução a um gênero mais vasto revelou-se perigosa para ela. Porque, cada vez mais, ela arrisca-se a ser vista somente como uma subimitação, uma subcrítica, uma subescrita ou uma simples "lingüística aplicada".

Existe uma maneira de definir a tradução a partir dela mesma, de defini-la como uma atividade específica? É uma questão que hoje em dia deve ser colocada.

De qualquer modo, o século XVI marca uma virada fundamental:

\footnotetext{
${ }^{22}$ L. Guillerm, op. cit., p. 20.
} 
pour la première fois dans l'histoire de l'Occident, l'acte de traduire est pourvu d'un nom propre. D'un nom propre, il est vrai, qui recèle une interprétation déterminée de cet acte et qui, ironiquement, renvoie au caractère «fautif» de toute traduction.

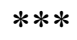

Pourvue d'un nom propre, l'opération traduisante va maintenant avoir un agent spécifique: le traducteur. Celui-ci se définit d'abord négativement: il n'est pas auteur, il n'est pas exégète, il n'est pas spécialiste des langues, mais il est un peu de tout cela. Cette curieuse définition a de lourdes conséquences sur le plan symbolique, sans parler des plans socio-professionnel et juridique. Quel est le «statut» du traducteur? Traduire est-il un «métier» et une «profession» de plein droit? Nous ne sommes pas sortis de ces questions, qui ont commencé à se poser au XVIe siècle.

Ce n'est pas un hasard si, à la Renaissance, apparaissent pour la première fois de grandes figures de traducteurs, de traducteurs dont on garde mémoire, comme on garde mémoire des grands auteurs.

Le XVIe siècle est donc l'époque où apparaissent simultanément la traduction et le traducteur, tous deux pourvus d'un nom propre. Aussi paradoxal que cela paraisse, traduction et traducteur ne sont pas nécessairement liés. La traduction peut exister sans traducteurs. Non pas, évidemment, sans des agents de la traduction, des traduisants, mais sans des traducteurs, c'est-à-dire des hommes ou des femmes dont la fonction essentielle consiste à faire des pela primeira vez na história do Ocidente, $\mathrm{o}$ ato de traduzir tem nome próprio. Um nome próprio, é verdade, que contém uma interpretação determinada desse ato e que, ironicamente, remete ao caráter "culposo" de toda tradução.

Tendo um nome próprio, o processo de tradução terá agora um agente específico: o tradutor. Esse se define primeiramente de forma negativa: não é autor, nem exegeta, nem especialista em línguas, mas é um pouco de tudo isso. Esta definição curiosa tem sérias conseqüências no nível simbólico, para não mencionar os sócio-profissional e legal. Qual é o "estatuto" do tradutor? Traduzir é um "trabalho" ou uma "profissão" de fato? Nós não estamos livres dessas questões, que começaram a surgir no século XVI.

Não é uma coincidência que, no Renascimento, apareceram pela primeira vez, grandes tradutores, tradutores que ficaram na memória, como ficam na memória os grandes autores.

O século XVI é a época em que surgem simultaneamente a tradução e o tradutor, ambos com um nome próprio. Por mais paradoxal que possa parecer, tradução e tradutor não são necessariamente ligados. A tradução pode existir sem tradutores. Não sem agentes da tradução, sem os que traduzem, mas sim sem tradutores, ou seja, homens ou mulheres, cuja função principal é fazer traduções. Nem todos os que traduzem são tradutores. 
traductions. Tout traduisant n'est pas traducteur.

Le XVIe siècle, d'ailleurs, semble avoir parfois oscillé entre ces deux termes. Ainsi Marot, dans un poème, emploie-t-il traduysant:

Grâces ne peult rendre assez suffisantes au tien Macault, ce gentil traduysant. ${ }^{23}$

Mais là encore, traducteur, plus actif que traduisant, finit par l'emporter. Cicéron, saint Jérôme, Oresme et Luther étaient plutôt de grands «traduisants». Car leur activité ne se limitait pas, loin de là, à la traduction. Ils tiraient même leur énergie de traduisants de leurs autres activités, et ne traduisaient pas «pour traduire».

À partir du XVIe siècle apparaît un être dont tout le faire se résume à traduire, dont tout le talent s'emploie à traduire, dont toute l'énergie se consume à traduire. En France, Amyot au XVIe siècle, Perrot d'Ablancourt au XVIIe siècle, Galland au XVIIIe, Hugo fils au XIXe, Leyris au XXe ne sont pour l'essentiel que des traducteurs.

Cette figure, le traducteur, qui émerge au XVIe siècle, n'évince pas le traduisant traditionnel: elle coexiste avec lui, souvent difficilement. Aujourd'hui encore, n'importe qui peut traduire, et même bien traduire: le traducteur n'a pas le monopole de la traduction. Mais s'il n'a pas acquis le monopole de la traduction comme le médecin a pour ainsi dire acquis le monopole des soins, il possède un profil propre, une psyché propre qui ne se confond avec nulle autre et qui, curieusement, n'a guère encore été étudiée. Amyot, en France, est un

\footnotetext{
${ }^{23}$ Auguste de Blignière, Essai sur Amyot et les traducteurs français au XVIe siècle (Genève, Slatkine reprints, 1968), p. 386v.
}

$\mathrm{O}$ século $\mathrm{XVI}$, aliás, parece ter às vezes oscilado entre estes dois termos. Assim, Marot, usa, em um poema, a palavra traduzinte:

Graças não pode encontrar suficientes
para Macault, aquele gentil traduzinte ${ }^{23}$.

Mas, novamente, o tradutor, mais ativo que o traduzinte, acaba dominando. Cícero, São Jerônimo, Oresme e Lutero eram os maiores "traduzintes". Pois as suas atividades não se limitavam à tradução. Eles buscavam a sua energia de traduzintes em suas outras atividades, e não traduziam "por traduzir".

A partir do século XVI, aparece um ser cujo trabalho se resume a traduzir, cujo talento se volta para a tradução, cuja energia se consome no traduzir. Na França, Amyot no século XVI, Perrot Ablancourt no século XVII, Galland, no 18, Hugo Fils no século XIX e Leyris no século XX são essencialmente tradutores.

Esta figura, a do tradutor, que surge no século XVI, não afasta o traduzinte tradicional: um convive com o outro, muitas vezes com dificuldade. Ainda hoje, qualquer um pode traduzir, e até traduzir bem: o tradutor não tem o monopólio da tradução. Mas ele não adquiriu o monopólio da tradução como o médico adquiriu o monopólio dos cuidados médicos : ele tem um perfil próprio, uma psique própria que não se confunde com nenhuma outra e que, curiosamente, não foi muito estudada. Amyot, na França, é um símbolo: é 
symbole: c'est (presque) le premier à avoir été essentiellement un traducteur.

Le traducteur est d'abord cet être qui a pour tâche de transférer un texte d'une langue à une autre, en général la sienne. A la différence du «translateur» médiéval, il se meut dans un monde où, désormais, les langues sont fermement délimitées. Et cela est fondamental. La tâche du traducteur consiste justement à transférer un texte d'une langue délimitée dans une autre langue délimitée, sans menacer cette délimitation mutuelle (par exemple en «anglicisant» indûment le français), mais aussi en enrichissant, par ce transfert, sa propre langue.

Le traducteur est ensuite cet être dont la tâche est de transférer un texte dont la propriété est définie, ce qui n'était pas le cas au moyen âge. Il doit «communiquer» le texte d'un individu ou d'une collectivité qui en sont symboliquement et juridiquement les auteurs, les propriétaires. Office qui, dès le XVIe siècle, sera considéré comme hautement important, mais aussi comme hautement suspect. Car le traducteur risque toujours et de brouiller les délimitations mutuelles des langues, et de compliquer les relations de propriété qui définissent tout texte dans le monde moderne.

Pourvue d'un nom propre, délimitée en ses contours, dotée d'un agent, pourvoyeuse et convoyeuse de savoir, la traduction va devenir au XVIe siècle l'objet d'un certain savoir, comme désormais la «langue maternelle». Ainsi que l'affirme Luce (quase) o primeiro a ter sido essencialmente tradutor.

O tradutor é primeiramente este ser que tem a tarefa de transferir o texto de um idioma para outro, geralmente o seu próprio. Ao contrário do "translador" medieval, ele se move em um mundo onde, agora, as línguas estão firmemente delineadas. E isso é fundamental. A tarefa do tradutor consiste justamente em transferir um texto de um idioma delimitado para outro idioma delimitado, sem comprometer essa delimitação mútua (por exemplo, ao anglicizar indevidamente o francês), mas também ao enriquecer, por esta transferência, a sua própria língua.

O tradutor é também este ser cuja tarefa é transferir um texto cuja propriedade é definida, o que não acontecia na Idade Média. Ele deve "comunicar" o texto de um indivíduo ou comunidade que são simbólica e legalmente os autores, os proprietários. Ofício que desde o século XVI, é considerado muito importante, mas também muito suspeito. Pois o tradutor sempre arrisca a misturar as delimitações mútuas das línguas e a complicar as relações de propriedade que definem todo texto no mundo moderno. 
Guillerm (mais il faudra nuancer l'affirmation), elle est devenue un «nouvel objet théorique». ${ }^{24}$

Le XVIe siècle, c'est certain, a plus écrit sur la traduction que l'Antiquité et le moyen âge réunis. Qu'estce que traduire? Quel est le rôle de la traduction? Quels en sont les enjeux? Les règles? La Renaissance pose ouvertement ces questions. Cela, aussi, est nouveau. C'est parce que la traduction a maintenant un nom propre et une figure unitaire qu'on peut en parler.

En vérité, ce que les hommes du XVIe siècle ont à nous dire sur la traduction n'est, pour l'essentiel, que la reprise de ce que Cicéron et saint Jérôme ont écrit sur ce thème. Il n'y a rien de nouveau, on l'a dit maintes fois, dans ce que la Renaissance énonce sur cette chose neuve, ou nouvellement redistribuée et nommée, qu'est la traduction. Mais là n'est pas l'essentiel.

Ce qui est nouveau, c'est que tout le monde parle de la traduction. Les traducteurs accompagnent leurs travaux de préfaces, d'explications, d'épitres dédicatoires, voire de poèmes, où ils présentent leurs traductions au public et à leurs commanditaires. Les arts poétiques et les traités de rhétorique ne manquent pas de consacrer des chapitres entiers à la traduction.

Certes, les «discours» du XVIe siècle sur la traduction ne sont absolument pas théoriques, si l'on entend par là une explicitation méthodique et conceptuelle de l'acte de traduire.

Plus qu'objet de connaissance, la traduction est pour les hommes de la Renaissance objet de discours. Et, (mas é preciso tomar a afirmação com reservas), tornou-se "um novo objeto teórico" 24 .

O século XVI, com certeza, escreveu mais sobre a tradução que a Antiguidade e a Idade Média juntos. O que é traduzir? Qual é o papel da tradução? Quais são os desafios? As regras? O Renascimento coloca abertamente estas questões. Isso também é novo. Porque a tradução tem um nome próprio e uma figura unitária é que se pode falar sobre ela.

$\mathrm{Na}$ verdade, o que os homens do século XVI têm a dizer sobre a tradução é somente, na essência, uma retomada do que Cícero e São Jerônimo escreveram sobre o tema. Não há nada de novo, como já dissemos muitas vezes, no que afirma o Renascimento sobre esta coisa nova, ou redistribuída novamente e nomeada, que é a tradução. Mas isso não é o essencial.

A novidade é que todo mundo fala da tradução. Os tradutores acompanham os seus trabalhos de prefácios, esclarecimentos, epístolas dedicatórias, até de poemas, onde apresentam suas traduções para o público e para os seus patrocinadores. As artes poéticas e os tratados de retórica não deixam de dedicar capítulos inteiros à tradução.

É certo que os "discursos" do século XVI sobre a tradução não são nada teóricos, se entendemos aqui uma explicação metódica e conceitual do ato da traduzir.

Mais do que um objeto de conhecimento, a tradução é para os homens do Renascimento objeto de dis-

\footnotetext{
${ }^{24}$ L. Guillerm, op. cit., p. 10.
} 
plus précisément encore, objet tout court, si «objet» signifie: ce qui est posé devant soi et offert par là au regard et à la considération d'un «sujet». Mais cet objet est bien particulier. D'abord, la pauvreté théorique des discours sur la traduction au XVIe siècle est contrebalancée par une grande richesse métaphorique. Tout se passe comme si la Renaissance ne pouvait cerner la traduction et le traducteur que par une multiplicité déroutante d'images.

Ensuite, ces discours, d'abord laudatifs, changent bien vite de ton. Luce Guillerm, qui a étudié attentivement une bonne partie des textes français du XVIe siècle consacrés à la traduction, ${ }^{25}$ a pu établir que ce changement intervient vers 1540 , soit trente ans après la mise en circulation du mot traduction en France. À partir de cette date, les textes sur la traduction et le traducteur deviennent généralement dépréciatifs. D'où un double paradoxe: le XVIe siècle est l'époque qui nomme et définit la traduction, mais aussi celle où, pour la première fois, ou du moins pour la première fois avec une telle force, la traduction est posée comme une activité négative et inférieure. Il est aussi l'époque où la traduction devient objet de discours; mais ce discours, loin de se constituer sur le mode du savoir conceptuel, ne peut cerner la traduction que sur le mode rhétorique et sur celui de la métaphore.

Les deux paradoxes sont liés, car les images de la traduction au XVIe siècle sont dans l'ensemble négatives.

La brutale dévalorisation de la traduction pendant la Renaissance est curso. E, mais especificamente, simples objeto, "objeto" significa: o que está posto diante si e oferecido sob o olhar e a consideração de um "sujeito". Mas esse objeto é muito especial. Primeiramente, a pobreza teórica do discurso sobre a tradução no século XVI foi compensada por uma grande riqueza metafórica. Tudo acontece como se o Renascimento só conseguisse definir a tradução e o tradutor por uma multiplicidade desconcertante de imagens.

Em segundo lugar, esses discursos mudam rapidamente de tom. Luce Guillerm, que tem estudado cuidadosamente uma boa parte dos textos franceses do século XVI dedicados à tradução ${ }^{25}$, pôde estabelecer que tal mudança ocorreu por volta de 1540 , ou seja, trinta anos após o surgimento da palavra tradução na França. A partir dessa data, os textos sobre tradução e o tradutor tornaramse em geral depreciativos. Daí um duplo paradoxo: o século XVI é a época que nomeia e define a tradução, mas é também a época na qual, pela primeira vez, ou pelo menos pela primeira vez com tanta força, a tradução é tratada como uma atividade negativa e inferior. É também a época em que a tradução se torna objeto de discurso; mas este discurso, longe de constituir-se sob o modo de conhecimento conceitual, só pode identificar a tradução sob o modo retórico e sob o da metáfora.

Ambos os paradoxos estão ligados, pois as imagens da tradução no século XVI são geralmente negativas.

A acentuada desvalorização da tradução durante o Renascimento é

\footnotetext{
${ }^{25}$ L. Guillerm, op. cit., p. 10.
} 
liée à un nom, celui de du Bellay, dont la Défense et illustration de la langue française (1549) est le refus le plus péremptoire de la traduction qui ait été exprimé en Occident. Cet ouvrage ne fait pas qu'exposer les idées personnelles de son auteur: il manifeste les choix profonds de toute une culture. Et il s'agit d'une autocondamnation de la traduction, puisque du Bellay était aussi, entre autres choses, un «traduysant».

Voici donc une activité qui, à peine née comme telle, se voit condamnée par ses propres agents, alors que les plus grandes traductions du siècle sont encore à venir, alors que les princes et le public soutiennent ouvertement les entreprises des traducteurs.

Pourquoi une telle condamnation? Pourquoi tant d'images négatives de la traduction? Mais d'abord: pourquoi tant d'images de la traduction? Nous tenterons de répondre à ces questions dans Jacques Amyot, traducteur français. ligada a um nome, o de du Bellay, cuja Defesa e ilustração da língua francesa (1549) é a recusa mais imperativa da tradução que foi expressa no Ocidente. Esse livro não expõe somente a opinião pessoal do seu autor: ele mostra as escolhas profundas de toda uma cultura. E se trata de uma autocondenação da tradução, já que du Bellay era também, entre outras coisas, um "traduzinte".

Eis uma atividade que, apenas nascida como tal, se vê condenada pelos seus próprios agentes, enquanto as maiores traduções do século ainda estão por vir, enquanto os príncipes e o público apóiam abertamente as empresas dos tradutores.

Por que tal condenação? Por que tantas imagens negativas da tradução? Mas, antes de mais nada: por que tantas imagens da tradução? Tentamos responder a essas perguntas em Jacques Amyot, tradutor francês.

Fonte: Berman, Antoine. "De la translation à la traduction", in TTR - Traduction, Terminologie, Rédaction. Études sur le texte et ses transformations. Volume 1, numéro 1, ler semestre de 1988. Université du Québec. 
ANTOINe Berman (1942-1991) foi tradutor, historiador, crítico e teórico da tradução. Apesar da vida curta e da obra não muito extensa, é considerado um dos fundadores da tradutologia moderna. Entre as suas maiores contribuições está o resgate das teorias que intelectuais alemães do período Clássico e Romântico dedicaram à tradução, responsáveis por formular uma estratégia estrangeirizante. Berman delimitou, a partir daí, o que chamou de "ética da tradução", uma ética que vai em direção ao Outro, negando práticas tradutórias etnocêntricas e anexadoras. Outra contribuição importante diz respeito à crítica de traduções. Em Pour une critique des traductions: John Donne, ele propõe um método para uma "crítica produtiva", que vá além das simples emissões de juízos de valor e que também considere a figura do tradutor.

No artigo acima, publicado originalmente na revista canadense TTR em 1988, Berman prossegue com o seu projeto de realizar uma "arqueologia da tradução na cultura ocidental". Desta vez, ele escava no solo do Renascimento, período de grande efervescência da atividade tradutória e também época em que o ato de traduzir passa a ser designado por um termo específico. Em uma investigação semântico-cultural, Berman rastreia o aparecimento do termo tradução no século 16 , que surge juntamente com uma mudança da percepção da sociedade européia em relação ao ato de traduzir. Ele nos situa sobre como funcionou a rede linguística em que atuava o tradutor medieval para demarcar as mudanças ocorridas no Renascimento. Ele também fixa nesse período o surgimento da figura do tradutor tal qual a vemos hoje, ou seja, o indivíduo que tem na tradução a sua principal atividade.

Pesquisadores e estudantes brasileiros que não têm acesso ao texto em francês têm à disposição, portanto, mais um fascinante estudo de Berman, que se soma às demais obras do autor traduzidas no Brasil, como $A$ tradução e a letra ou o albergue do longínquo (7Letras/UFSC, 2007) e A prova do estrangeiro (Edusc, 2002), além dos artigos Traduire: Écrire ou Désécrire / Traduire: Escrever ou Descrever (Scientia Traductionis, $\mathrm{n}^{\circ}$ 7, 2010) e A tradução e seus discursos (Revista Alea, vol. 11, n. 2, 7Letras/UFRJ, 2009).

\author{
Marlova Aseff \\ marlova.aseff@gmail.com
}

Scientia Traductionis, n.9, 2011 